\title{
Risk classification paradox of anthropometric measurements in Saudi Arabia: need for further consideration
}

\author{
M.M. Alkhalaf, C.A. Edwards, M.E.J. Lean and E. Combet \\ Human Nutrition, New Lister Building, School of Medicine, College of Medical, Veterinary and Life Sciences, \\ University of Glasgow, Glasgow G31 2ER, UK
}

Lifestyle (including dietary habits) and socioeconomic status have changed in Saudi Arabia (SA) over the last decades. SA suffers from a high burden of non-communicable diseases (NCDs) such as cardiovascular diseases, hypertension and type 2 diabetes mellitus, fuelled by obesity and overweight ${ }^{(1)}$. A steep population increase ( $75 \%$ in just over 10 years) and a young population (63\% aged under 30) implies that the burden of NCDs will increase further in the forthcoming decades ${ }^{(2)}$. Monitoring overweight and obesity in SA is therefore an urgent imperative to develop adequate public health policies. This study aims to integrate current national surveys to build a comprehensive picture of overweight and obesity in SA, discussing the use of body mass index and waist circumference as best descriptors.

We carried out secondary analysis of data obtained from five Saudi national and sub-national surveys (Saudi Health Information Survey $2013^{(1)}$, National Health Survey 2004-2005 (3), Capital-wide Biomarker Screenings in Riyadh region 2008-2009 and 2013$2014^{(4)}$, and the Riyadh Validation Survey $\left.2013^{(5-6)}\right)$. Participants (18 years old and over) had been randomly selected from the community for all surveys. Height, weight, waist and hip circumferences (WC, HC) were measured after informed consent. Body weight $(\mathrm{kg})$ was divided by height $(\mathrm{m})$ squared to generate BMI (body weight $(\mathrm{kg}) / \mathrm{height}\left(\mathrm{m}^{2}\right)$ ). Obesity was defined according to BMI $\left(\geq 30 \mathrm{~kg} / \mathrm{m}^{2}\right)$ and risk associated with large waists was determined based on established WC cut-offs: $\left.i\right)$ elevated risk 1 - $q>$ $80 \mathrm{~cm}$ and $\hat{\delta}>94 \mathrm{~cm}$; ii) high-risk 2: $q>88 \mathrm{~cm}$ and $\hat{\delta}>102 \mathrm{~cm}$. Data was analysed using the Statistical Package for Social Sciences (SPSS) software, version 21.0 for Windows (SPSS Inc., Chicago, IL, USA). Data from the five surveys were combined into a single database. Subjects were grouped into fifteen 10-year age bands, identified by the middle year from 25 (that is, ages 18-27) to 95 (ages 88-97) years. Subjects were also divided into two age groups: $<45$ years old and $>45$ years old. Spearman's correlations and regression analyses were performed to determine the relationship between body composition and age within each gender.

A total of $n=24,689$ adults were included in the analysis (55\% female, $45 \%$ male). The median age was 40 years (IQR $29-52$ ). Complete anthropometric measurements were available for $n=12,744$ participants $(52 \%) ; 45 \%$ of women and $31 \%$ of men were obese; $51 \%$ of women and $35 \%$ of men had a large waist (elevated and high risk). Linear regression analysis showed significant increase in body weight, waist circumference and BMI for every 5 years increase in age $(\mathrm{p}<0.001): 1.35 \mathrm{~kg} ; 2.1 \mathrm{~cm}$ and $0.72 \mathrm{~kg} / \mathrm{m}^{2}$ in women; and $0.32 \mathrm{~kg} ; 1.27 \mathrm{~cm}$ and $0.27 \mathrm{~kg} / \mathrm{m}^{2}$ in men, respectively. The magnitude of the difference in prevalence of obesity and having a large waist in women and men was statistically significant $\left(\chi^{2}=494.7 ; \chi^{2}=565.6\right.$ respectively, both $\left.p<0 \cdot 0001\right)$. Around $25 \%$ of the women and $30 \%$ of the men with a very large waist (high-risk 2) would not have been identified as high-risk based on their (nonobese) BMI. Among those aged $>45$ years with a BMI between 18.5-25, 59\% of women and $34 \%$ of men had a large waist (risk 1 or 2), approximately twice as many as those aged under 45 with a normal BMI ( $24 \%$ of women, $16 \%$ of men with elevated large waist).

SA experiences high prevalence of obesity, compounded by the fact that half of older adults $(\sim 42 \%)$ not categorised as obese based on BMI in fact have a large waist. The use of BMI may be misleading as a measure of adiposity across populations especially in older people. It is necessary to investigate further whether BMI and WC are better predictors of health outcomes (metabolic risks) among Saudi Arabs since the current cut-offs derived from a European Caucasian population.

1. El Bcheraoui C et al. (2014) Inter jour of pub heal. 59, 1011-1021.

2. Ministry of Economy and Planning (2015). Central Department of Statistics and Information.

3. WHOSTEPwise (2005) World Health Organization /Regional Office for the Eastern Mediterranean.

4. Al-Daghri NM et al.et al (2011) BMC Med, 9, 1-6.

5. Alkhalaf MM, Edwards CA, Combet E (2015) Proc Nutr Soc 74, OCE1, E22.

6. Alkhalaf MM, Edwards CA, Lean MEJ, Combet E (2015) Proc Nutr Soc 74, OCE2, E170. 